\title{
RANCANG BANGUN ALAT TAMBAL BAN DALAM SEPEDA MOTOR
}

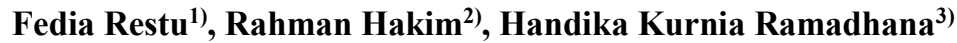 \\ 1,2,3) Program Studi D3 Teknik Mesin, Jurusan Teknik Mesin, Politeknik Negeri Batam \\ E-mail: fedia@polibatam.ac.id ${ }^{1)}$
}

\begin{abstract}
ABSTRAK
Dalam dunia otomotif, alat tambal ban sangatlah dibutuhkan untuk memberikan solusi sementara apabila terdapat ban bocor selain harus membeli ban yang baru. Kebocoran ban merupakan salah satu kendala saat mengendarai sepeda motor, terutama jika mengalami kebocoran pada bagian sisi valve, karena alat tambal ban biasa tidak dapat menambal pada bagian sisi valve. Untuk meminimasi biaya yang harus dikeluarkan tersebut maka dalam penelitian ini dibuatlah rancang bangun alat tambal ban agar dapat meminimalisir biaya pada saat terjadi kendala saat berkendara sepeda motor yaitu pada saat ban bocor. Konsep penambahan fungsional alat tambal ban ini adalah yaitu pada alat penekan ban dalam diberi lubang yang seukuran dengan valve ban, sehingga valve ban tersebut dapat masuk ke lubang tersebut. Dengan invensi pada alat tambal ban ini bagian yang bocor di bagian sisi valve ban dalam dapat ditambal. Penelitian ini dilakukan dengan metode observasi dan melakukan desain dengan analisa perbandingan biaya yang didapatkan alat ini lebih ekonomis dibandingkan dengan alat tambal ban yang beredar biasanya
\end{abstract}

kata kunci : valve, alat penekan, pecah ban

\section{ABSTRACT}

In the automotive world, tire filling tools needed to provide temporary solutions if there are leaky tires in addition to having to buy a new tire. Tire leakage is one of the obstacles when riding a motorcycle, especially if you leak on the side of the valve because ordinary tire patching tools cannot patch on the bottom of the lid. To minimize the costs, the design of this tire patching tool designed to reduce costs when obstacles arise when riding a motorcycle, which is when a tire leaks. The concept of the functional addition of the tire filling tool is that the inner tire pressure tool has given a hole the size of a tire valve so that the tire valve can enter the pit. With the invention of this tire patch tool, the leaking portion on the side of the inner tire valve to be patched. This research conducted to the method of observation and design with a comparative analysis of the costs obtained by this tool is more economical than the tire patching tools that are in circulation normally.

\section{Keywords: valve, press tool, flat tire}

\section{PENDAHULUAN}

Pengendara sepeda motor selalu mempunyai permasalah saat mempunyai roda tipe non tubeless, ketika terjadi kebocoran ban dalam sepeda motor, tidak semua pengendara langsung mengganti dengan ban yang baru. alasannya karena ban dalam motor mereka masih layak untuk digunakan. Selain itu, jika dilihat dari segi ekonomi, biaya yang harus dikeluarkan pengendara untuk menambal ban dalam lebih murah jika dibandingkan dengan ban dalam baru (Jama \& Wagino, 2008).

Adanya keluhan yang terjadi di masyrakat saat mempunyai sepeda motor salah satunya adalah ketika ban dalam tersebut bocor pada bagian sisi valve (Jama \& Wagino, 2008). Alat tambal ban yang dimiliki bengkel-bengkel tambal ban tidak memadai untuk menambal ban yang bocor pada bagian sisi valve. Tentu saja pengendara harus mengganti ban dalam yang baru. hal tersebut tentu saja merugikan bagi pengendara sepeda motor. Pada alat tambal ban ini dengan membuat alat tambal ban yang dimana pada bagian alat penekan ban tersebut diberi lubang yang seukuran dengan besar valve ban, sehingga valve ban dapat masuk ke dalam lubang alat penekan.

Berdasarkan pengindentifikasian tersebut dapat disimpulkan bahwa mengindentifikasi suatu masalah berguna untuk mendapatkan hal yang faktual. Kebutuhan-kebutuhan yang perlu dipenuhi harus didefinisikan secara luas dan dikenali solusisolusi yang memungkinkan (Mendagri, 2010). Dibuatnya alat tambal ban ini adalah guna mencari solusi apabila sedang mengalami kebocoran ban pada bagian valve (Hakim dkk, 2019).

Selain itu terdapat juga beberapa inovasi tentang alat tambal ban tetapi tidak sama dengan alat tamba ban ini. Diantaranya bisa dilakukan pencarian pada laman pdki-indonesia.go.id seperti terlihat pada Gambar 1 dengan nomor paten: S00200600125 , yang menjelaskan tentang alat tambal ban elektrik (Zamzami, dkk. 2016). Alat tambal ban tersebut menggunakan sistem listrik pada saat proses pemanasannya. Tetapi pada alat tambal ban elektrik tersebut tidak dapat menambal di bagian sisi valve ban dalam (Satrio, 2012) 
Tujuan dari penelitian ini adalah untuk membuat alat tambal ban yang dimodifikasi agar dapat mengurangi pengeluaran biaya pada saat mengalami kebocoran tanpa mengganti ban dalam. Tentu saja alat tambal ban ini lebih efektif dibanding alat tambal ban pada umumnya.

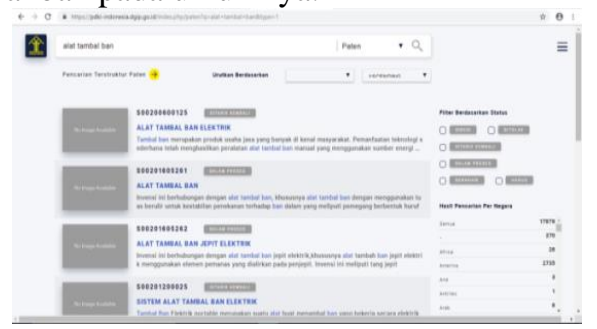

Gambar 1. Penelusuran laman pdki-indonesia.dgip.go.id

\section{METODOLOGI PENELITIAN}

Penelitian kali ini dilakukan dengan cara observasi lapangan terhadap kejadian sehari-hari yang sering terjadi pada saat berkendara sepeda motor. Yang dimana kita ketahui biasanya pada setiap bengkel tambal ban di pinggir jalan hanya memiliki alat tambal ban biasa yang tidak dapat menambal di bagian sisi valve ban dalam. Selain dari penelitian secara observasi dilakukan juga pencarian alat serupa pemilik paten alat tambal ban pada laman pdki-indonesia.dgip.go.id dengan kata kunci pencarian : Alat tambal ban. Dalam pencarian tersebut terdapat beberapa hasil, namun tidak relevan dengan inovasi alat tambal ini.

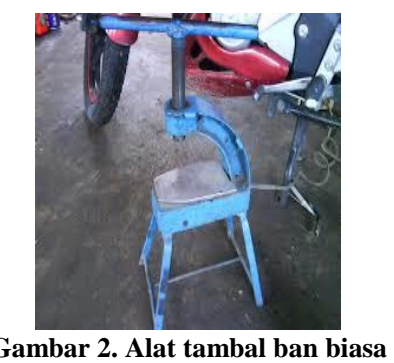

Gambar 2 diatas merupakan alat tambal ban sederhana yang digunakan bengkel tambal ban di pinggir jalan.

Metode penelitian pembuatan alat sebagai berikut :

\section{a. Observasi Lapangan}

Proses ini bertujuan untuk mengumpulkan sebanyak mungkin informasi yang ada dilapangan tentang kondisi kebutuhan spesifikasi yang harus dipenuhi oleh produk. Berdasarkan observasi yang dilakukan alat tambal ban sederhana ini sangat membantu keluhan masyrakat mengenai ban yang bocor di bagian sisi valve ban dalam.

\section{b. Studi Literatur}

Proses ini diawali dengan pengumpulan data, dasar teori, literatur dari berbagai sumber yang digunakan sebagai sumber acuan dan referensi dalam mendesain alat. Dalam kegiatan ini juga mencari materi penunjang dari buku dan hal-hal yang berhubungan dalam proses desain alat tambal ban ini.

\section{c. Proses Desain Dengan SolidWorks}

Proses desain alat menggunakan aplikasi solidworks. Alat didesain tidak jauh berbeda dari alat tambal ban pada umumnya. Namun pada alat tambal ban ini dibuat berbeda pada alat penekan yang diberi lubang untuk tempat memasukkan valve ban.

\section{d. Evaluasi dan Analisa Produk}

Sebelum melangkah pada proses desain alat, desain yang telah ada terlebih dahulu di evaluasi dan di analisa apa saja kekurangan dan kelebihan pada saat digunakan. Hal ini bertujuan untuk mengetahui inovasi apa yang akan dilakukan pada alat tambal ban tersebut.

\section{e. Pembuatan Gambar Detail}

Setelah desain sudah dibuat sesuai ukuran dan desain telah dinyatakan sesuai referensi, maka di buat gambar detail dari desain alat tambal ban tersebut. Gambar detail berupa penambahan beberapa bagian penunjang alat.

\section{f. Pembelian Alat dan Bahan}

Setelah proses survey dilakukan, proses selanjutnya adalah pembelian alat dan bahan apa saja yang akan digunakan pada saat membuat alat tambal ban tersebut.

\section{g. Proses Pembuatan Alat}

Langkah selanjutnya setelah semua alat dan bahan telah ada langsung pada proses pembuatan alat. Pembuatan alat dilakukan setelah semua rancangan dan desain yang telah dibuat terlebih dahulu.

\section{h. Pengujian Alat}

Pengujian dilakukan untuk mengetahui apakah alat tersebut sudah sesuai dengan apa yang diinginkan. Pada pengujian alat bisa ditambahkan alat-alat penunjang lainnya.

\section{i. Penyusunan Laporan}

Jika semua proses sudah dilakukan, langkah terakhir adalah penyusunan laporan. penyusunan laporan dilakukan untuk mengetahui kegiatan-kegiatan yang dilakukan serta proses dan biaya pada pembuatan alat ini.

\subsection{Alat-alat Penelitian}

A. Software Solidwork : aplikasi atau perangkat lunak yang digunakan untuk membantu proses desain alat tambal ban ini

B. Measuring :

1) Jangka Sorong/ Caliper

2) Mistar

3. ANALISA DATA DAN PEMBAHASAN 
Pembuatan inovasi alat tambal ini adalah guna untuk menanggapi keluhan yang sering terjadi di masyarakat yaitu, pada saat mengalami kebocoran pada bagian sisi valve ban dalam. Yang sebelumnya jika pengendara diharuskan mengganti ban dalam tersebut, sekarang sudah tidak perlu mengganti ban tersebut karena masih dapat ditambal dengan alat tambal ini, sehingga dapat meminimalisir keuangan jika terjadi kebocoran ban saat berkendara

\subsection{Perancangan Kerangka Alat Tambal Ban}

Alat tambal ban yang terdiri dari beberapa bagian yaitu, Base, Handle and long thread, dan Pressing/ alat penekan. Bagian-bagian tersebut disesain menggunakan Software Solidworks.

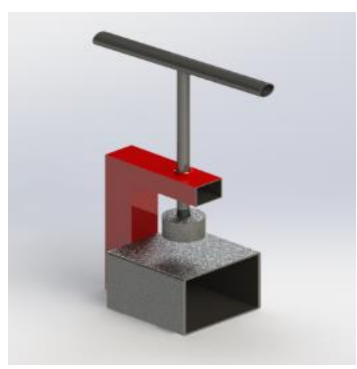

Gambar 3. Alat tambal ban desain dengan Solidwork

Gambar 3 diatas merupakan gambar dari rancangan alat tambal ban yang didesain menggunakan software solidwork.

\subsubsection{Base}

Base berfungsi sebagai tempat di letakkannya ban dalam pada saat dipress/tekan. Bagian base dibentuk tidak jauh berbeda dari alat tambal ban yang sudah ada. Pada bagian base disambungkan dengan besi hollow sebagai penyangga atau badan dari tempat meletakkan handle dan long thread dengan alat penekan.

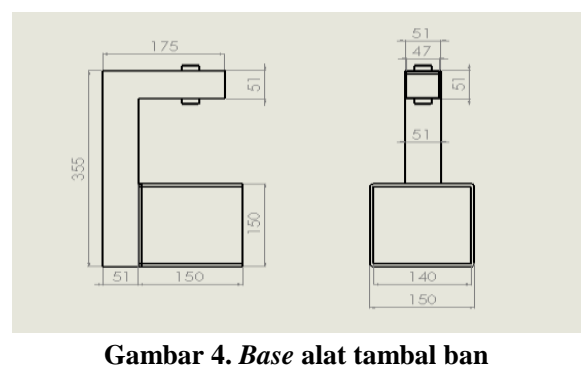

Gambar 4 diatas merupakan gambar dari bagian base alat tambal ban.

\subsubsection{Handle dan Long Thread Rod}

Handle merupakan bagian untuk memegang pada saat akan memutar alat penekan. Bagian handle disambungkan dengan long thread (batang besi panjang yang berulir) yang berguna sebagai penekan dengan cara kerja seperti baut dan mur. Sistem perputaran yang akan mengakibatkan gaya tekan antara handle dan long thread dengan alat penekan. Berikut dibawah merupakan gambar alat handle dan long thread rod

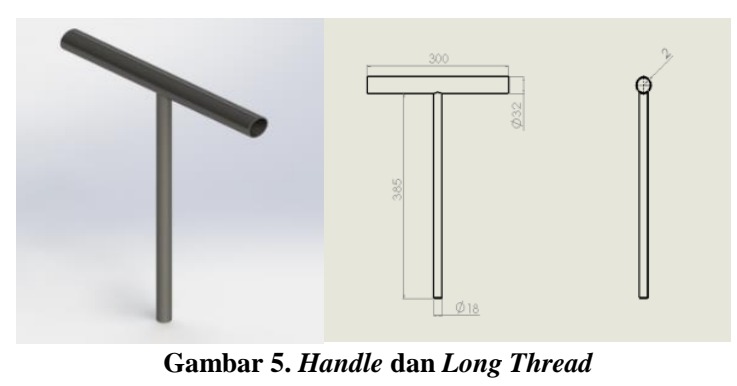

Gambar 5 diatas merupakan gambar dari bagian handle dan long thread rod alat tambal ban

\subsubsection{Pressing / alat penekan}

Pressing berfungsi sebagai penekan ban ke base pada saat melakukan pemanasan. Alat pressing tersebut disambungkan dengan alat penyambung handle dan long thread. Alat pressing tersebut berdiameter $60 \mathrm{~mm}$. Pada alat penekan diberi lubang dibawah dengan ukuran diameter $17 \mathrm{~mm}$ dan kedalaman $35 \mathrm{~mm}$ untuk tempat valve ban agar dapat masuk kedalam.

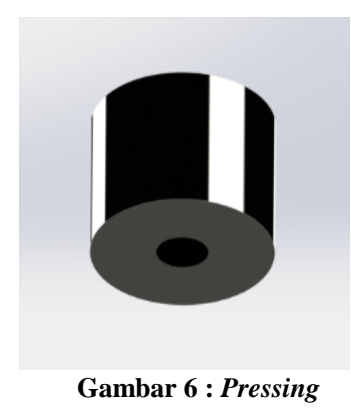

Gambar 6 diatas merupakan gambar dari bagian pressing alat tambal ban

\subsection{Analisa Aspek Ergonomi Alat}

Perancangan yang baik dapat dihasilkan dengan mengenal sifat-sifat, keterbatasan, serta kemampuan yang dimiliki manusia. Manusia berperansentral dalam aktivitasnya yaitu sebagai perencana, perancang, pelaksana, dan pengevaluasian dalam setiap aktivitas (kerja). Manusia sebagai sumber tenaga kerja masih dominan dalam menjalankan proses produksi terutamakegiatan yang bersifat berulang. 
Perancangan peralatan secara ergonomis perlu dilakukan yang berpedoman pada prinsip- prinsip ergonomi (Wignjosoebroto, 2008)

Ergonomi dapat didefinisikan sebagai studi tentang aspek-aspek manusia dalam lingkungan kerjanya ditinjau secara anatomi, fisiologi, psikologi, engineering, manajemen, dan desain/perancangan. Ergonomi berkenaan dengan optimasi, efisiensi, kesehatan, keselamatan, dan kenyamanan manusia di tempat kerja, rumah, dan dimana saja manusia berada (Nurmianto, 2004).

Sebelum melakukan perancangan alat juga tentu saja kita harus memperhatikan aspek ergonomi dari alat tersebut. Alat tambal ban ini dirancang sedemikian rupa agar mudah digunakan oleh kalangan masyarakat, seperti bagian handle stick yang dibuat supaya memudahkan memegang pada saat akan melakukan penekanan.

\subsection{Sistem kerja Alat}

Sistem kerja alat tambal ban ini cukup sederhana yaitu, pertama menggunakan teori lead screw sebagai penggerak yang mengakibatkan gaya tekan, kedua sistem pemanasan menggunakan kompor minyak atau kompor gas kecil.
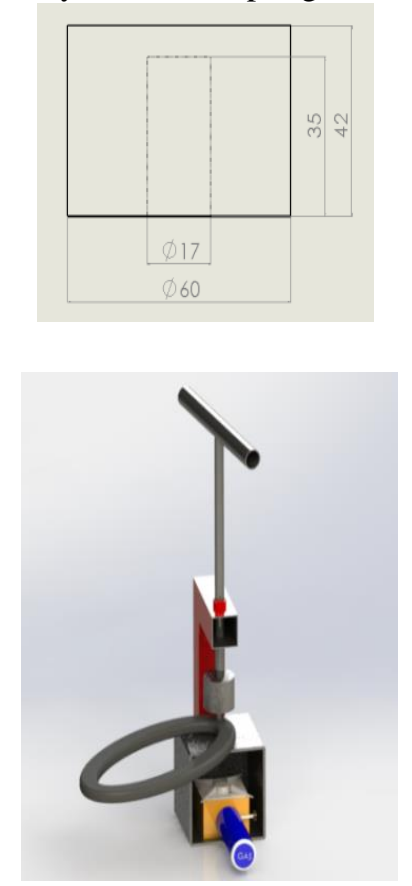

Gambar 7. Alat tambal ban assembly full

Gambar 7 diatas merupakan gambar alat tambal ban yang sudah di assembly.

\subsubsection{Lead Screw}

Lead screw adalah poros berulir yang merupakan pengubah gerakan dengan memanfaatkan gaya tekan akibat perputaran ulir menjadi gerakan linier. Prinsip kerjanya sebenernya seperti pasangan mur dan baut, ketika mur diputar maka akan didapatkan pergerakan linier dari bautnya. Dengan mekanisme kerja demikian tadi lead screw dapat memudahkan pekerjaan manusia. Salah satu penerapan lead screw adalah pada alat tabal ban.

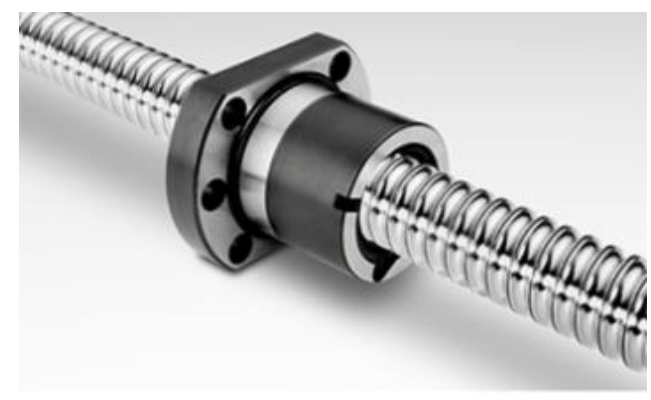

Gambar 8. Lead Screw

Gambar 8 diatas merupakan gambar sistem kerja lead screw. Sistem kerjanya seperti mur dan baut.

\subsubsection{Sistem Pemanas}

Sistem pemanas alat tambal ban ini yaitu menggunakan kompor kompor gas kecil (Cengel dan Boles, 2010). Proses pemanasan kurang lebih 510 menit (Yunus, 2009).

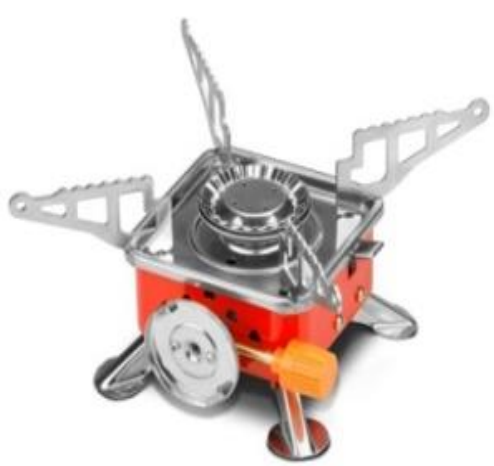

Gambar 9. Kompor gas kecil

Gambar 9 diatas merupakan gambar dari kompor gas yang digunakan sebagai pemanas.

\subsection{Analisa Biaya dan Proses Pembuatan Alat \\ - Biaya Pembuatan Alat}

Tabel 1. Biaya pembuatan alat

\begin{tabular}{|c|c|c|c|c|}
\hline No & Nama Item & Qty & Harga Satuan & Harga Total \\
\hline 1 & $\begin{array}{l}\text { Plat Besi Hitam } \\
150 \mathrm{~mm} \times 170 \mathrm{~mm}\end{array}$ & 5 & $\mathrm{Rp} 6.000,00$ & $\mathrm{Rp} 30.000,00$ \\
\hline 2 & $\begin{array}{l}\text { Long thread } \\
\curvearrowleft 18 \mathrm{~mm} \times 50 \mathrm{~cm}\end{array}$ & 1 & $\mathrm{Rp} 35.000,00$ & $\mathrm{Rp} 35.000,00$ \\
\hline 3 & $\begin{array}{l}\text { Besi round bar } \\
\varnothing 60 \mathrm{~mm} \times 50 \mathrm{~mm}\end{array}$ & 1 & $\mathrm{Rp} 5.000,00$ & $\mathrm{Rp} 5.000,00$ \\
\hline 4 & $\begin{array}{c}\text { Besi hollow kotak } \\
51 \mathrm{~mm} \times 51 \mathrm{~mm} \times 50 \mathrm{~cm}\end{array}$ & 1 & $\mathrm{Rp} 12.000,00$ & $\mathrm{Rp} 12.000,00$ \\
\hline 5 & $\begin{array}{l}\text { Besi hollow bulat } \\
ø 18 \mathrm{~mm} \times 30 \mathrm{~cm}\end{array}$ & 1 & $\mathrm{Rp} 4.000,00$ & $\mathrm{Rp} 4.000,00$ \\
\hline 6 & $\begin{array}{l}\text { Biaya Machinning dan } \\
\text { Pengelasan }\end{array}$ & 1 & Rp $100.000,00$ & Rp 100.000,00 \\
\hline \multicolumn{4}{|c|}{ Harga Total } & Rp $186.000,00$ \\
\hline
\end{tabular}


Berdasarkan tabel biaya pembuatan alat diatas, diperoleh harga total pembuatan alat yaitu, $\mathrm{Rp}$ $186.000,00$

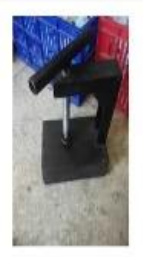

Alat Tambal Ban Dalam Press Pres Bakar IDR 205,000.00 Shopee

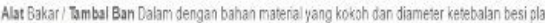
mencapai +4 min (home made

\section{- Harga Online Alat}

Gambar 10. Harga online alat tambal ban

Gambar 10 diatas merupakan harga online dari alat tambal ban pada umumnya.

\subsubsection{Analisa Kelayakan Ekonomis}

Berdasarkan perbandingan biaya pembuatan alat dengan harga alat tambal ban online harga pembuatan alat lebih murah dibandingkan dengan harga online. Dengan spesifikasi yang sama dengan menggunakan bahan bakar untuk proses pemanasan, tetapi pada alat tambal ban ini dapat menambal pada bagian sisi valve ban dalam, karena pada alat penekan diberi lubang agar valve tersebut dapat masuk. Tentu saja alat ini menjawab permasalahan masyarakat dan sesuai dengan kebutuhan masyrakat ,terutama bagi usaha mikro kecil menengah (UMKM), serta menghasilkan nilai tambah dari aspek ekonomi dan lingkungan.

\subsubsection{Proses Pembuatan Alat}

Berikut merupakan proses pengerjaan alat tambal ban :

1) Proses Machining ( Milling dan Bubut)

Pertama yang dilakukan adalah pengerjaan menggunakan mesin milling. Proses yang dilakukan adalah pemakanan facing yaitu, untuk mendapatkan ketebalan plat yang diinginkan. Tebal plat awal adalah $6 \mathrm{~mm}$, pemakanan facing yang dilakukan sebanyak $1 \mathrm{~mm}$ dengan menggunakan endmill diameter $10 \mathrm{~mm}$ agar mendapatkan ketebalan plat $5 \mathrm{~mm}$. Lakukan proses tersebut terhadap 5 plat besi yang tersedia.

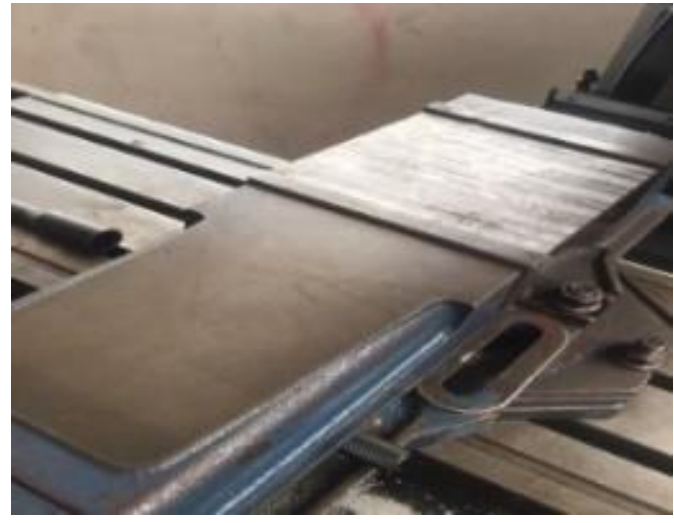

Gambar 11. Proses milling

Kedua yang dilakukan adalah pengerjaan menggunakan mesin bubut. Proses yang dilakukan hampir sama yaitu pemakanan facing untuk mendapatkan diameter alat penekan yang diinginkan. Setelah itu lakukan proses pengeboran pada alat penekan tersebut dengan mata bor $10 \mathrm{~mm}$ dengan kedalaman 15 mm. Lubang tersebut adalah untuk memasukkan valve pada alat penekan.

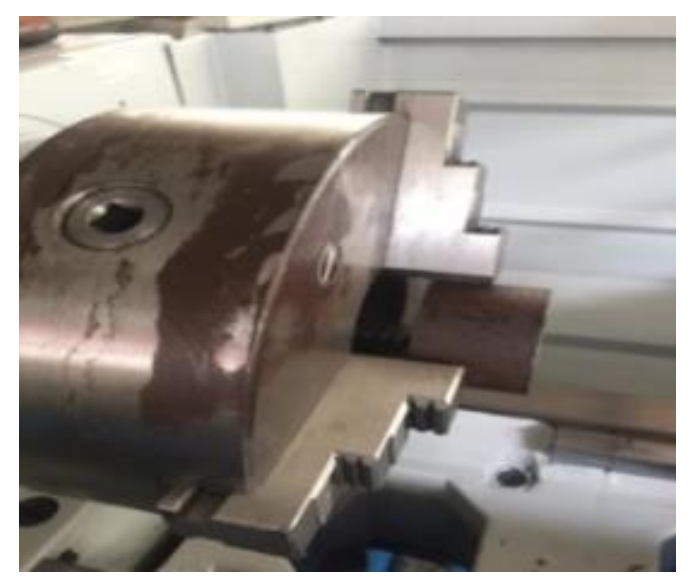

Gambar 12. Proses Bubut

2) Proses Pengelasan

Setelah proses machining langkah selanjutnya adalah pengelasan semua bagianbagian yang telah dikerjakan. Seperti bagian base dengan badan penyangga dan long thread dengan handle serta alat penekan. 


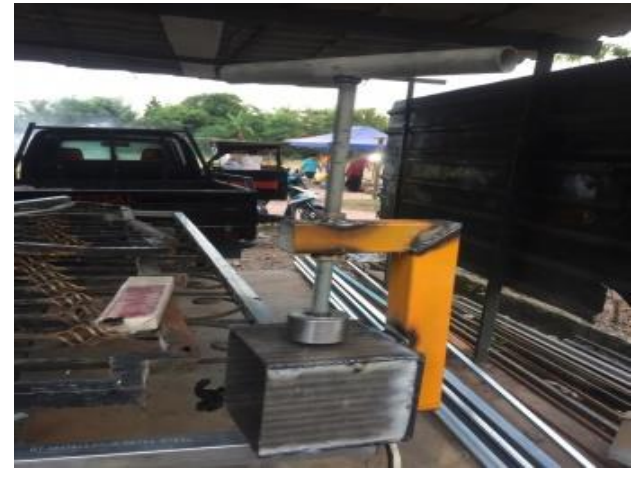

Gambar 13. Proses pengelasan

3) Finishing

Proses terakhir yaitu finishing untuk merapikan alat tambal ban tersebut agar terlihat lebih menarik.

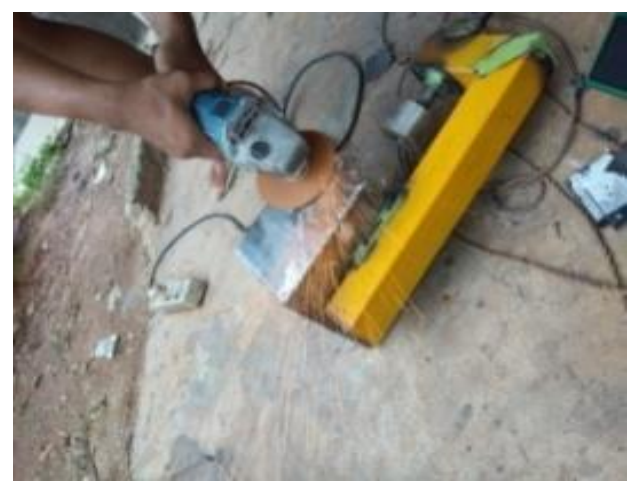

Gambar 14. Proses finishing

4) Bentuk Alat

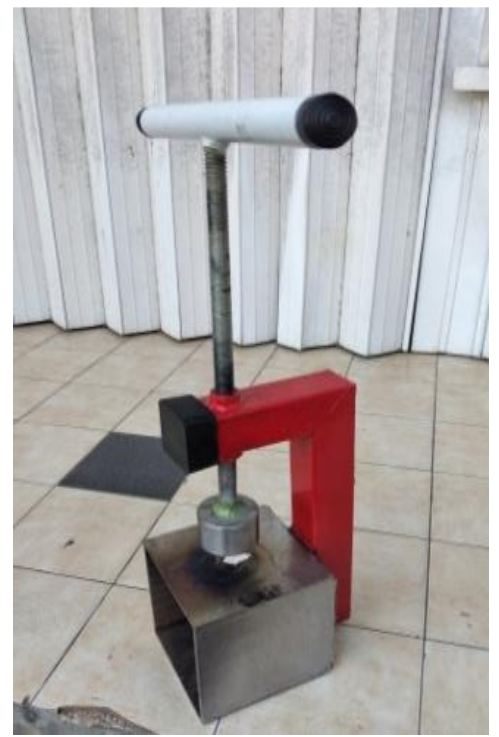

Gambar 15. Bentuk jadi alat tambal ban

\section{- Cara Kerja Alat}

Berikut merupakan cara kerja alat tambal ban :

> Putar handle kearah atas guna mendapatkan ruang untuk meletakkan ban dalam yang sudah diberi lem atau kompon di bagian ban yang bocor pada bagian sisi valve.

> Putar handle ke bawah guna menjepit dan mendapatkan gaya tekan antara alat penekan dengan ban menuju bagian base. Pastikan valve ban dalam masuk ke dalam lubang alat penekan tersebut. Putar dengan kencang agar ban dijepit secara benar agar pada saat pemanasan dapat menyebar secara rata.

> Sebelum ban dijepit, lakukan pengikisan atau gosok bagian ban yang bocor menggunakan kikir atau bisa menggunakan benda tajam lainnya seperti gergaji besi.

$>$ Setelah itu, tempel karet penambal pada bagian yang telah digosok.

> Pada bagian base diberi alumunium foil atau kertas biasa agar pada saat pemanasan, karet penambal tidak lengket.

$>$ Nyalakan sumber pemanas bisa berasal dari kompor gas kecil, lalu letakkan pada slot yang tersedia pada bagian badan alat tambal ban tersebut.

> Biarkan selama kurang lebih 5-10 menit agar panas bisa merata dengan baik.

> Matikan api dari pemanas jika sudah mancapai waktunya. Biarkan ban tersebut dingin terlebih dahulu.

> Setelah itu, putar handle ke atas untuk melepaskan jepitan alat penekan dengan ban dalam.

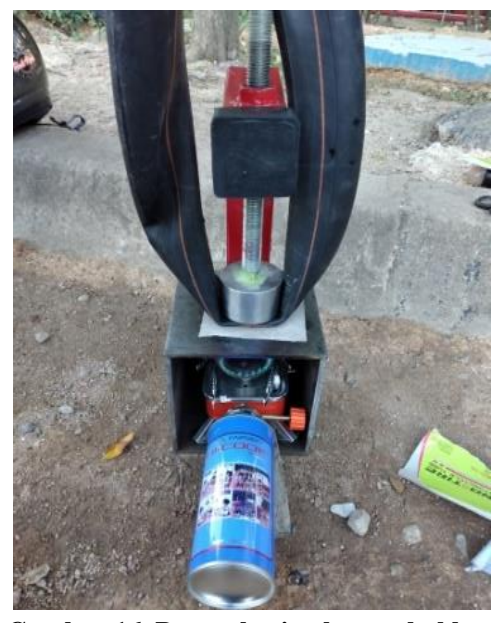

Gambar 16. Proses kerja alat tambal ban

Gambar 16 diatas merupakan gambar proses cara kerja dari alat tambal ban tersebut. 
Tabel 1. Hasil Pengujian Alat

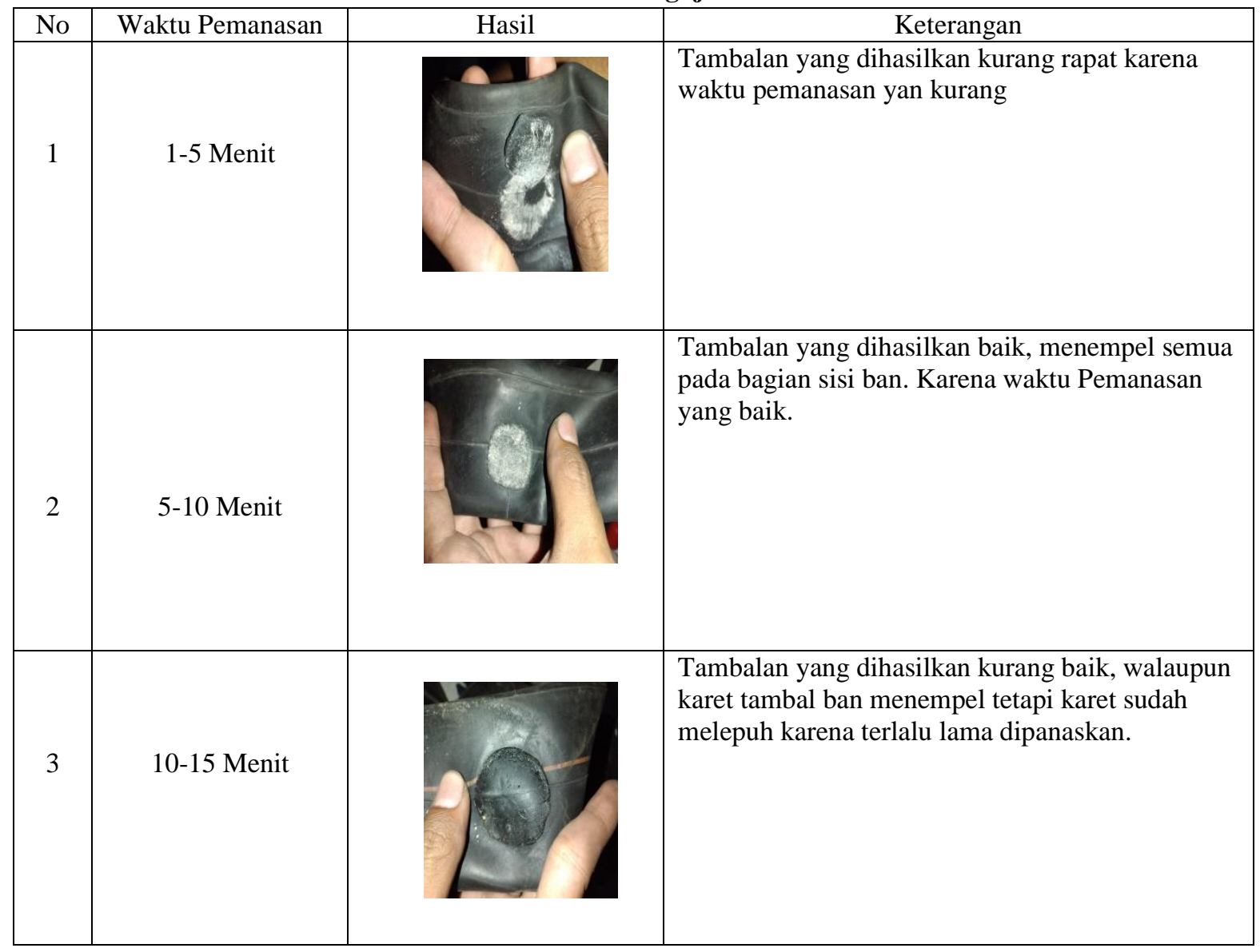

Berdasarkan tabel hasil pengujian alat di atas didapatkan beberapa hasil pengujian dari beberapa percobaan. Pada percobaan dengan waktu 1-5 menit tambalan yang dihasilkan kurang baik karena tambalan tidak rapat, percobaan waktu 5-10 menit tambalan yang dihaasilkan baik, sedangkan percobaan waktu 10-15 menit tambalan yang dihasilkan kurang baik juga karena karet sudah melepuh.

\section{KESIMPULAN}

Dari semua tahapan yang sudah dilakukan dapat diambil kesimpulan :

- Alat tambal ban ini merupakan pengembangan dari alat tambal ban biasanya, karena pada alat tambal ban ini diberi penambahan fungsional yang bisa menambal pada bagian sisi valve ban dalam

- Dengan diciptakannya alat tambal ban ini semoga dapat membantu masyarakat saat mengelami kebocoran ban pada bagian sisi valve ban dalam. Karena dengan alat ini masyarakat tidak perlu mengganti ban dalam jika terjadi kebocoran pada bagian sisi valve ban dalam.

- Sistem kerja alat menggunakan sistem lead screw yaitu poros berulir yang merupakan sebagai pengubah gerakan dengan memanfaatkan gaya tekan akibat perputaran ulir menjadi gerakan linier. dan proses pemanasan menggunakan kompor gas kecil.

\section{DAFTAR PUSTAKA}

Cengel, Y.A., Boles, M.A. 2010. “ Thermodynamics : An Engineer Approach 7th Edition". McGraw-Hill.

Hakim, R., dkk. 2019. "Alat Bantu dan Pengarah Pentil Pada Mesin Tambal Ban", DJKI S00201911527.

Jama, J., Wagino. 2008. “Teknik Sepeda Motor”. Jakarta: Departemen Pendidikan Nasional.

Mendagri. 2010. Permendagri No. 20/2010 tentang Pemberdayaan Masyarakat Melalui Pengelolaan Teknologi Tepat Guna

Nurmianto, Eko. 2004. " Ergonomi : konsep dasar dan aplikasinya". Surabaya : Guna Widya.

Satrio, A. W. 2012. " Alat tambal ban elektrik dengan pendekatan value engineering (Skripsi tidak diterbitkan)". Fakultas Teknik Industri Universitas Wijaya Putra, Surabaya.

Wignjosoebroto, S. 2008. “ Ergonomic Studi Gerak dan Waktu: Teknik Analisis untuk Peningkatan Produktivitas Kerja ". Guna Widya, Surabaya, 35-80, 2008. 
Yunus, A.D. 2009. “ Perpindahan Panas dan Massa Teknik Mesin". Universitas Dharma Persada, Jakarta.

Zamzami, R., Alfian, M.A., Maulana, I.L. 2016.

“Alat Tambal Ban”, DJKI S00201605261. 